Silje Kvistad, MD

Kjell-Morten Myhr, PhD

Trygve Holmøy, PhD

Jūrate Šaltyte Benth, PhD

Kristin I. Løken-Amsrud, $\mathrm{PhD}$

Stig Wergeland, $\mathrm{PhD}$

Antonie G. Beiske, PhD

Kristian S. Bjerve, $\mathrm{PhD}$

Harald Hovdal, MD

Finn Lilleås, MD

Rune Midgard, $\mathrm{PhD}$

Tom Pedersen, MD

Søren J. Bakke, MD

Øivind Torkildsen, PhD

Correspondence to

Dr. Kvistad:

sgns@helse-bergen

\title{
No association of tobacco use and disease activity in multiple sclerosis
}

OPEN

\section{ABSTRACT}

Objective: To study whether tobacco use is associated with MRI and clinical disease activity in patients with multiple sclerosis (MS).

Methods: Prospective cohort study of 87 patients with relapsing-remitting MS originally included in a randomized placebo-controlled trial of omega-3 fatty acids in MS (the OFAMS Study). Serum levels of cotinine (biomarker of tobacco use) were analyzed at baseline and every 6 months for 2 years. MRI activity was assessed at baseline and monthly for 9 months and after 12 and 24 months.

Results: Fifty-three patients (61\%) had serum cotinine levels $\geq 85 \mathrm{nmol} / \mathrm{L}$ on $\geq 60 \%$ of the measurements and were considered tobacco users and 34 (39\%) had cotinine levels $<85 \mathrm{nmol} / \mathrm{L}$, consistent with non-tobacco use. There was no association between tobacco use and the occurrence of new gadolinium-enhancing T1 lesions, new or enlarging T2 lesions, or their aggregate (combined unique activity). Furthermore, there was no association between cotinine levels and MRI activity for the tobacco users, and tobacco users did not have more relapses or Expanded Disability Status Scale progression.

Conclusion: Our results indicate that tobacco use does not directly influence MRI activity or relapse rate in MS. This may implicate that the reported association between smoking and MS disease progression could be mediated through other mechanisms. Neurol Neuroimmunol Neuroinflamm 2016;3:e260; doi: 10.1212/NXI.0000000000000260

\section{GLOSSARY}

BMI = body mass index; $\mathbf{C l}=$ confidence interval; EDSS $=$ Expanded Disability Status Scale; HLA = human leukocyte antigen; IFN- $\boldsymbol{\beta}-\mathbf{1} \mathbf{a}=$ interferon beta-1a; $\mathbf{M S}=$ multiple sclerosis; $\mathbf{O R}=$ odds ratio; RRMS = relapsing-remitting multiple sclerosis; SPMS = secondary progressive multiple sclerosis; T1Gd = T1-weighted gadolinium-enhanced.

Multiple sclerosis (MS) is an inflammatory disease of the CNS. The etiology is unknown, but there seems to be an interaction between genetic and environmental risk factors. ${ }^{1}$ Several human leukocyte antigen (HLA) subtypes are known to increase the risk of MS, ${ }^{2}$ and several environmental factors such as low serum vitamin D levels, Epstein-Barr virus infection, and smoking are associated with MS. ${ }^{3,4}$

Smoking is a known risk factor for developing MS. ${ }^{3,5-8}$ Smokers with clinically isolated syndrome have been reported to have earlier progression to clinically definitive MS than nonsmokers, ${ }^{9}$ and smoking has been suggested to decrease the time for disease conversion from

\footnotetext{
From the Department of Immunology and Transfusion Medicine (S.K.), Norwegian Multiple Sclerosis Competence Centre, Department of Neurology (S.K., S.W., Ø.T.), and Norwegian Multiple Sclerosis Registry and Biobank, Department of Neurology (K.-M.M., S.W., Ø.T.), Haukeland University Hospital, Bergen; KG Jebsen MS Research Centre (S.K., K.-M.M., Ø.T.), Department of Clinical Medicine, University of Bergen; Department of Neurology (T.H.), and HØKH, Research Centre (J.Š.B.), Akershus University Hospital, Lørenskog; Institute of Clinical Medicine (T.H., J.Š.B.), University of Oslo; Department of Neurology (K.I.L.-A.), Innlandet Hospital Trust, Lillehammer; Multiple Sclerosis Centre Hakadal (A.G.B.); Clinic of Laboratory Medicine (K.S.B.) and Department of Neurology (H.H.), St. Olavs Hospital, Trondheim University Hospital; Department of Laboratory Medicine (K.S.B.), Children's and Women's Health, Norwegian University of Science and Technology, Trondheim; Curato Oslo (F.L.); Department of Neurology (R.M.), Molde Hospital; Unit for Applied Clinical Research (R.M.), Norwegian University of Science and Technology, Trondheim; Unilabs Drammen (T.P.), Drammen; and Department of Neuroradiology (S.J.B.), Oslo University Hospital Rikshospitalet, Norway.

Funding information and disclosures are provided at the end of the article. Go to Neurology.org/nn for full disclosure forms. The Article Processing Charge was paid by the University of Bergen.

This is an open access article distributed under the terms of the Creative Commons Attribution-NonCommercial-NoDerivatives License 4.0 (CC BY-NC-ND), which permits downloading and sharing the work provided it is properly cited. The work cannot be changed in any way or used commercially.
} 
relapsing-remitting MS (RRMS) to secondary progressive MS (SPMS). ${ }^{10-14}$ It has been suggested that smoking influences the clinical progression in MS and several studies have explored this, with conflicting results. ${ }^{12,15,16}$ One study has reported that smoking cessation decreases the risk of Expanded Disability Status Scale (EDSS) progression, ${ }^{14}$ but a recent report did not find any association between tobacco use and MS activity or progression over a 5 -year follow-up. ${ }^{17}$

To address the effect of tobacco use in established MS, we examined the associations among serum cotinine levels, MRI, and clinical disease activity in a 2-year longitudinal study of 87 HLA-DRB1*15-typed patients with RRMS.

METHODS Standard protocol approvals, registrations, and patient consents. The study was approved by the Regional Committee for Medical and Health Research Ethics in Western Norway Regional Health Authority, and all participants gave written informed consent.

Study participants and design. The study design has been presented previously. ${ }^{18-20}$ In brief, this was a cohort study of 87 patients with RRMS according to the McDonald criteria originally included in a randomized placebo-controlled trial of omega- 3 fatty acids at 13 Norwegian MS centers from December 2004 until July 2008 (the OFAMS [ $\omega-3$ Fatty Acid Treatment in Multiple Sclerosis] Study). Included patients had $\geq 1$ clinical relapse, a new T1-weighted gadolinium-enhanced MRI (T1Gd)-positive lesion or enlarging T2 lesions in the last 12 months before enrollment. The patients were followed for 24 months with thorough examinations including serum samples, MRI scans, and clinical scorings. MRI scans were performed at baseline and monthly for 9 months and then after 12 and 24 months according to a standardized protocol. ${ }^{18}$ The sum of T1Gd+ lesions and new or enlarging T2 lesions was denoted as combined unique activity. Clinical data were recorded by experienced neurologists, including EDSS scores every 6 months and clinical relapses throughout the study period. The patients did not use any immune modulatory drugs at inclusion, but from month 6, all patients started subcutaneous injections with $44 \mu \mathrm{g}$ of interferon beta-1a (IFN- $\beta$-1a) (Rebif; Merck KGaA, Darmstadt, Germany) 3 times weekly. All patients were randomized to receive omega-3 fatty acids (Triomar; Pronova Biocare AS, Sandefjord, Norway) or placebo (corn oil) daily throughout the study period. Since no effects from omega-3 fatty acid supplementation on MS disease activity were detected in any part of the study, all patients were pooled in the current analysis.

Measurements. Cotinine is a nicotine metabolite with a half-life of 15 to 40 hours. It is the most widely used biomarker for recent tobacco use and has a high sensitivity $(96 \%-97 \%)$ and specificity $(99 \%-100 \%) .{ }^{21}$ The serum levels reflect tobacco exposure during the prior 3 to 5 days. Serum samples were stored at $-80^{\circ} \mathrm{C}$ until analysis, which was performed simultaneously for all samples from each patient. The laboratory technicians were blinded for the clinical and radiologic status of the patients. Serum levels of cotinine were measured using liquid chromatography tandem mass spectrometry at Bevital AS (Bergen, Norway). The method was highly sensitive and specific with a lower limit of detection at $1 \mathrm{nmol} / \mathrm{L}$. The within-day coefficient of variation was $2.0 \%$ to $6.6 \%$ and the between-day coefficient of variation was $3.9 \%$. We analyzed serum samples from patients at baseline and months $6,12,18$, and 24 .

Cotinine levels $>85 \mathrm{nmol} / \mathrm{L}$ are indicative of recent tobacco use $^{22}$ and are regarded as the optimal cutpoint widely used for distinguishing tobacco users from non-tobacco users in the general population. ${ }^{21}$ Cotinine has the advantage over other tobacco biomarkers that the optimal cutpoints are little affected by the prevalence of smoking in the population sampled. ${ }^{23}$ This is also the cutoff value recommended by Bevital AS, the laboratory where the serum analyses were performed. ${ }^{24}$

The patients were categorized into 2 groups according to serum cotinine level. Patients with serum cotinine level $\geq 85$ $\mathrm{nmol} / \mathrm{L}$ in $\geq 60 \%$ of the samples were considered tobacco users and patients with serum cotinine levels $<85 \mathrm{nmol} / \mathrm{L}$ in $\geq 60 \%$ of the samples were considered non-tobacco users.

The HLA-DRB ${ }^{*} 15$ analyses have been described previously. ${ }^{18,20,25}$

Missing values. A total of 9 MRI scans (1 during study months $1-6$ and 8 during study months $7-24$ ) were missing. Seven blood samples for serum cotinine analysis were missing for months 0 to 6 and 39 were missing for months 7 to 24 .

Statistics. Data were described as frequencies and percentages or means and SDs, as appropriate. The differences in number of relapses and baseline EDSS scores among smokers and nonsmokers were assessed using independent-samples $t$ test.

The association between tobacco use and MRI activity was assessed using a logistic regression model for hierarchical data. The model contained fixed effect for smoking status and random effects for intercepts correctly adjusting the estimates for intrapatient correlations. The model was estimated for total study period as well as for periods before and during IFN- $\beta$ - 1 a treatment. All models were also adjusted for sex, age, body mass index (BMI), and HLA-DRB1*15 status. The association between cotinine levels and MRI activity among tobacco users (serum cotinine $\geq 85 \mathrm{nmol} / \mathrm{L}$ ) was also assessed by a logistic regression model for hierarchical data with fixed effect for cotinine level and random effects for intercepts.

All tests were 2 -sided. Results with $p$ values $<0.05$ were considered statistically significant. The analyses were performed in SAS version 9.4 (SAS Institute, Cary, NC) and SPSS version 22 (IBM Corp., Armonk, NY).

RESULTS Cotinine levels and MRI disease activity. Of 87 patients, 53 (61\%) had cotinine levels $>85 \mathrm{nmol} / \mathrm{L}$ in $\geq 60 \%$ of the samples and were considered tobacco users, and $34(39 \%)$ were considered non-tobacco users. Most patients had consistent cotinine levels on all samples, but $11(13 \%)$ had consistent levels in $75 \%$ of the measurements and $4(5 \%)$ in $60 \%$ of the measurements. There was no association between tobacco use and MRI activity, for new T1Gd + lesions (odds ratio $[\mathrm{OR}]=0.76 ; 95 \%$ confidence interval $[\mathrm{CI}]$ $0.41-1.43 ; p=0.39$ ), for new or enlarging $\mathrm{T} 2$ lesions $(\mathrm{OR}=0.81 ; 95 \%$ CI $0.42-1.56 ; p=0.52)$, and for combined unique activity $(\mathrm{OR}=0.81 ; 95 \%$ CI $0.43-$ $1.53 ; p=0.51)$ for the total study period. The result was consistent for the 6 months before and 18 months 
during IFN- $\beta-1 \mathrm{a}$ treatment. Adjusting for sex, age, BMI, and HLA-DRB1*15 status did not influence our results (table). Similarly, when only analyzing tobacco users by logistic regression model for hierarchical data, there was no association between cotinine levels and MRI activity during the 2-year follow-up $(\mathrm{OR}=0.98$; 95\% CI 0.94-1.04; $p=0.52)$.

Cotinine levels and clinical disease activity. A total of 42 relapses were recorded in 23 patients, of which 14 occurred during the first 6 study months. There was no difference in number of relapses between the tobacco users and non-tobacco users, with a mean number of relapses of $0.42(\mathrm{SD}=0.77)$ for tobacco users and 0.59 $(\mathrm{SD}=1.18)$ for non-tobacco users $(p=0.41)$.

There was no difference in baseline EDSS score between tobacco users (mean of 1.92, SD $=0.85$ ) and non-tobacco users (mean of $1.85, \mathrm{SD}=0.84$ ) $(p=0.7)$. During the study period, 26 patients progressed $\geq 1$ EDSS point. A total of $19(37 \%)$ of the tobacco users had EDSS progression compared to $7(21 \%)$ of the non-tobacco users, but the difference was not significant $(p=0.14)$.

DISCUSSION In this cohort of patients with MS, we could not detect any association between tobacco use, assessed by serum cotinine levels, and MRI or clinical disease activity.

This study was performed in a well-characterized cohort of patients with RRMS prospectively followed for 2 years with repeated and paired MRI scans and measurements of cotinine levels both before and during IFN- $\beta$ - 1 a treatment. The results were adjusted for sex, age, BMI, and HLADRB1*15 status. All MRI, biochemical, and clinical assessments were performed with strict and standardized procedures.
There are some limitations to our study. We used serum cotinine levels as a proxy for smoking behavior, but being a marker for tobacco use, the levels will also be high among snuff users or users of nicotine gum, and one study has suggested possible protective effects of these considering MS risk. ${ }^{26}$ The total proportion of smokeless tobacco of all tobacco consumption in Norway during the study period was, however, less than $20 \%$ and even lower among women. ${ }^{27}$ It is therefore reasonable to assume that the cotinine levels in our samples mainly reflect smoking. The patients were classified as tobacco users or non-tobacco users based on cotinine level in $\geq 60 \%$ of the measurements, and there is a risk of misclassification, possibly mostly for light smokers since the half-life of serum cotinine is 15 to 40 hours. However, we had serum measurements at 5 different time points and most patients had consistent serum cotinine levels on all measurements, indicating that this is not a major issue. It has also been demonstrated that serum cotinine levels are well correlated with patient-reported smoking behavior. ${ }^{28}$ The follow-up period of 24 months is relatively short and our results might have been different with longer follow-up. However, our findings are in coherence with those of a recently published study with a follow-up period of 5 years. ${ }^{17}$ Also, the lack of any of the results being even close to significant toward influence of tobacco use on MRI disease activity make it unlikely that there is any association. Our MRI findings were supported by no association between cotinine levels and clinical disease activity. The follow-up period was short and few relapses were reported, thus the sensitivity for clinical activity is low. However, our main outcome was MRI activity, which is a sensitive and well-known assessment for subclinical disease activity.

\section{Table \\ Odds ratios for MRI disease activity associated with tobacco use (serum cotinine $\geq 85 \mathrm{nmol} / \mathrm{L}$ ) in patients with relapsing-remitting}

multiple sclerosis

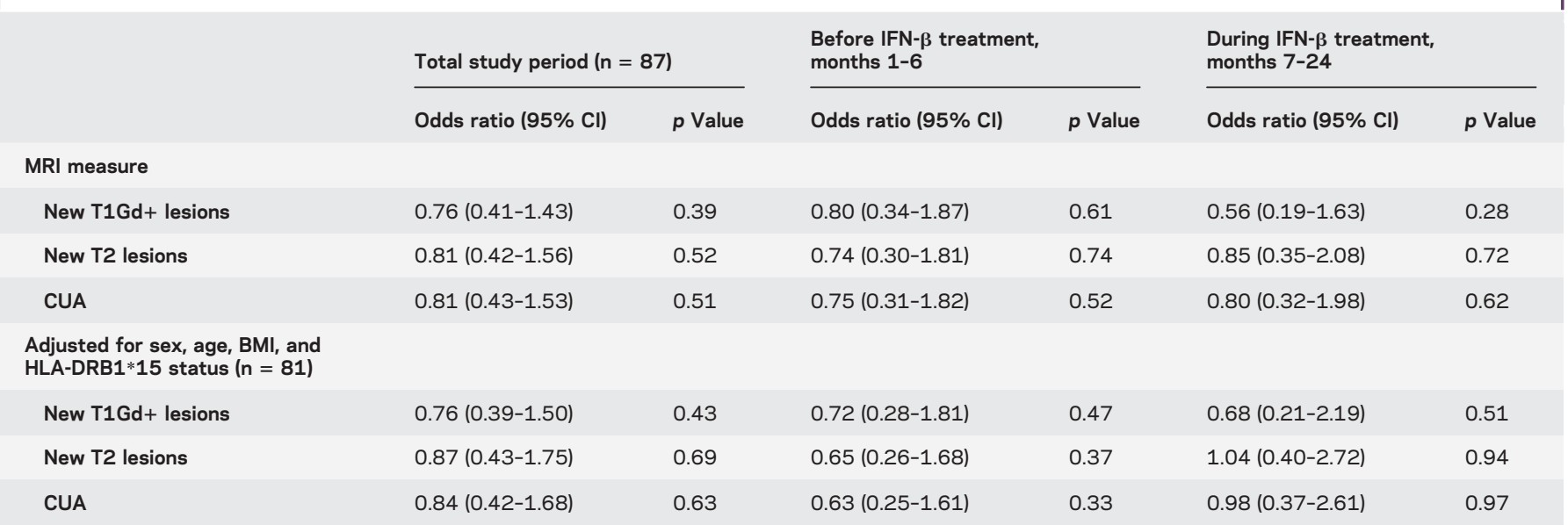

Abbreviations: $\mathrm{BMI}=$ body mass index; $\mathrm{Cl}=$ confidence interval; CUA $=$ combined unique activity; IFN $-\beta=$ interferon beta; T1Gd $=$ T1-weighted gadolinium-enhanced. 
The lack of any association between smoking and EDSS progression in our study could be attributable to the relatively short follow-up time of 24 months, and the fact that few patients experienced EDSS progression during the study period. A number of earlier studies have reported increased risk of disease progression among smokers. ${ }^{14,15}$ The mechanism for this association is largely unknown, but one possibility could be that smoking increases the inflammatory activity in MS. It has been demonstrated in the experimental autoimmune encephalitis model of MS that proinflammatory $\mathrm{T}$ cells are activated in the lungs before they attack the brain. ${ }^{29}$ Although our negative results may implicate that this mechanism does not have a major role in patients with established MS, they do not exclude this possibility, or that smoking has an important role during the initiation phase of the disease. Smoking is one of the most attractive and studied environmental risk factors for MS. The first reports on an association between MS and smoking were published in the $1990 \mathrm{~s},{ }^{30,31}$ and since then, a number of studies have confirmed smoking as a risk factor for MS. ${ }^{5-7,26,32}$ Even passive smoking has been associated with MS. ${ }^{33}$ Recent studies have also described the association between cotinine levels in serum and the risk of MS. ${ }^{34,35}$ Previous reports have found an association with clinical disease and earlier progression from clinically isolated syndrome to RRMS and from RRMS to SPMS among smokers. ${ }^{10-13,36}$ However, others have not been able to confirm an association between smoking and the risk of MS or an earlier progression to SPMS in smokers. ${ }^{16,37}$ Only a few studies have examined how smoking influences disease activity in MS. One study explored the association between MRI lesions in MS and smoking and found that the T2-weighted lesion volume increased faster in smokers, ${ }^{10}$ and a recently published study reported no association between MRI activity and serum cotinine levels. ${ }^{17}$ The result of our study supports this latter report. Other hypothesized mechanisms of adverse effects of smoking in MS include chronic cyanide intoxication leading to demyelination, the direct effect of cigarette-smoke components on the blood-brain barrier and smoking-mediated increased frequency and persistence of infections. ${ }^{11}$ There are also several other possible reasons for the increased impairment and disability in patients with MS who smoke and it is not clear whether it is a direct effect of tobacco use or a consequence of comorbidities associated with smoking. ${ }^{38}$

Our results do not support a short-term (2 years) influence of tobacco use on MRI and clinical disease activity in MS. Long-term effects and the importance of comorbidities influenced by smoking in MS need to be explored.

\section{AUTHOR CONTRIBUTIONS}

Silje Kvistad: study concept and design, acquisition of data. Kjell-Morten Myhr: study concept and design, analysis and interpretation, acquisition of data, critical revision of the manuscript for important intellectual content, study supervision. Trygve Holmøy: analysis and interpretation, critical revision of the manuscript for important intellectual content. Jürate Šltyte Benth: analysis and interpretation. Kristin I. Løken-Amsrud, Stig Wergeland: critical revision of the manuscript for important intellectual content. Antonie G. Beiske, Kristian S. Bjerve, Harald Hovdal, Finn Lilleås, Rune Midgard, Tom Pedersen, Søren J. Bakke: acquisition of data, critical revision of the manuscript for important intellectual content. Øivind Torkildsen: study concept and design, analysis and interpretation, acquisition of data, critical revision of the manuscript for important intellectual content, study supervision.

\section{STUDY FUNDING}

No targeted funding.

\section{DISCLOSURE}

S. Kvistad received research support from Novartis, Biogen. K.-M. Myhr served on the scientific advisory board for Novartis Norway, Biogen, Genzyme, Roche, received travel funding from Sanofi-Aventis, Novartis, Biogen, received speaker honoraria from Genzyme, Sanofi-Aventis, Novartis, Biogen, Roche, Almirall, received research support from Sanofi-Aventis, Novartis, Biogen, ProNova, Norwegian MS Society. T. Holmøy received speaker honoraria from Merck Serono, SanofiAventis, Biogen Idec, Novartis, Genzyme, is an editorial board member for Journal of the Norwegian Medical Association, The Open Virology Journal, Future Neurology, received research support from Merck Serono, Norway. J.S. Benth and K.I. Løken-Amsrud report no disclosures. S. Wergeland received speaker honoraria from Biogen, Novartis. A.G. Beiske served on the scientific advisory board for Genzyme, received travel funding from Teva, has been an author for Nyhetsbulletinen, received research support from Novartis. K.S. Bjerve and H. Hovdal report no disclosures. F. Lilleås reports no disclosures. R. Midgard served on the scientific advisory board for Novartis Norway, received travel funding and/or speaker honoraria from Novartis Norway. T. Pedersen reports no disclosures. S.J. Bakke served on the scientific advisory board for Norvasc, received travel funding from ASNR, was a scientific advisor for the Norwegian Medical Association, receives royalties for a textbook. $\varnothing$. Torkildsen served on the scientific advisory board for Biogen, SanofiAventis, Merck. Go to Neurology.org/nn for full disclosure forms.

Received February 29, 2016. Accepted in final form June 2, 2016.

\section{REFERENCES}

1. Hedstrom AK, Bomfim IL, Barcellos LF, et al. Interaction between passive smoking and two HLA genes with regard to multiple sclerosis risk. Int J Epidemiol 2014; 43:1791-1798.

2. Goris A, Pauwels I, Dubois B. Progress in multiple sclerosis genetics. Curr Genomics 2012;13:646-663.

3. Ascherio A, Munger KL. Environmental risk factors for multiple sclerosis: part II: noninfectious factors. Ann Neurol 2007;61:504-513.

4. Ascherio A, Munger KL. Environmental risk factors for multiple sclerosis: part I: the role of infection. Ann Neurol 2007;61:288-299.

5. Hernan MA, Olek MJ, Ascherio A. Cigarette smoking and incidence of multiple sclerosis. Am J Epidemiol 2001;154: 69-74.

6. Handel AE, Williamson AJ, Disanto G, Dobson R, Giovannoni G, Ramagopalan SV. Smoking and multiple sclerosis: an updated meta-analysis. PLoS One 2011;6: e16149.

7. Wingerchuk DM. Smoking: effects on multiple sclerosis susceptibility and disease progression. Ther Adv Neurol Disord 2012;5:13-22. 
8. Riise T, Nortvedt MW, Ascherio A. Smoking is a risk factor for multiple sclerosis. Neurology 2003;61:1122-1124.

9. Di Pauli F, Reindl M, Ehling R, et al. Smoking is a risk factor for early conversion to clinically definite multiple sclerosis. Mult Scler 2008;14:1026-1030.

10. Healy BC, Ali EN, Guttmann CR, et al. Smoking and disease progression in multiple sclerosis. Arch Neurol 2009;66:858-864.

11. Hernan MA, Jick SS, Logroscino G, Olek MJ, Ascherio A, Jick H. Cigarette smoking and the progression of multiple sclerosis. Brain 2005;128:1461-1465.

12. Pittas F, Ponsonby AL, van der Mei IA, et al. Smoking is associated with progressive disease course and increased progression in clinical disability in a prospective cohort of people with multiple sclerosis. J Neurol 2009;256: 577-585.

13. Roudbari SA, Ansar MM, Yousefzad A. Smoking as a risk factor for development of secondary progressive multiple sclerosis: a study in IRAN, Guilan. J Neurol Sci 2013;330: 52-55.

14. Ramanujam R, Hedstrom AK, Manouchehrinia A, et al. Effect of smoking cessation on multiple sclerosis prognosis. JAMA Neurol 2015;72:1117-1123.

15. Manouchehrinia A, Tench CR, Maxted J, Bibani RH, Britton J, Constantinescu CS. Tobacco smoking and disability progression in multiple sclerosis: United Kingdom cohort study. Brain 2013;136:2298-2304.

16. Koch M, van Harten A, Uyttenboogaart M, De Keyser J. Cigarette smoking and progression in multiple sclerosis. Neurology 2007;69:1515-1520.

17. Munger KL, Fitzgerald KC, Freedman MS, et al. No association of multiple sclerosis activity and progression with EBV or tobacco use in BENEFIT. Neurology 2015;85: 1694-1701.

18. Torkildsen O, Wergeland S, Bakke S, et al. $\omega-3$ Fatty Acid Treatment in Multiple Sclerosis (OFAMS Study): a randomized, double-blind, placebo-controlled trial. Arch Neurol 2012;69:1044-1051.

19. Kvistad S, Myhr KM, Holmoy T, et al. Antibodies to Epstein-Barr virus and MRI disease activity in multiple sclerosis. Mult Scler 2014;20:1833-1840.

20. Loken-Amsrud KI, Holmoy T, Bakke SJ, et al. Vitamin D and disease activity in multiple sclerosis before and during interferon- $\beta$ treatment. Neurology 2012;79:267-273.

21. SRNT Subcommittee on Biochemical Verification. Biochemical verification of tobacco use and cessation. Nicotine Tob Res 2002;4:149-159.

22. Connor Gorber S, Schofield-Hurwitz S, Hardt J, Levasseur G, Tremblay M. The accuracy of self-reported smoking: a systematic review of the relationship between self-reported and cotinine-assessed smoking status. Nicotine Tob Res 2009;11:12-24.

23. Jarvis MJ, Tunstall-Pedoe H, Feyerabend C, Vesey C, Saloojee Y. Comparison of tests used to distinguish smokers from nonsmokers. Am J Public Health 1987;77:1435-1438.

24. BEVITAL AS. About the biomarkers, cotinine [online]. Available at: http://www.bevital.no/. Accessed April 20, 2016.

25. Loken-Amsrud KI, Myhr KM, Bakke SJ, et al. Alphatocopherol and MRI outcomes in multiple sclerosis: association and prediction. PLoS One 2013;8:e54417.

26. Hedström AK, Baarnhielm M, Olsson T, Alfredsson L. Tobacco smoking, but not Swedish snuff use, increases the risk of multiple sclerosis. Neurology 2009;73:696-701.

27. Folkehelseinstituttet. Rusmidler i Norge 2014 [online]. Available at: https://www.fhi.no/globalassets/dokumenterfiler/ rapporter/rin2014norsk.pdf. Accessed April 20, 2016.

28. Baltar VT, Xun WW, Chuang SC, et al. Smoking, secondhand smoke, and cotinine levels in a subset of EPIC cohort. Cancer Epidemiol Biomarkers Prev 2011;20:869-875.

29. Odoardi F, Sie C, Streyl K, et al. T cells become licensed in the lung to enter the central nervous system. Nature 2012;488:675-679.

30. Villard-Mackintosh L, Vessey MP. Oral contraceptives and reproductive factors in multiple sclerosis incidence. Contraception 1993;47:161-168.

31. Thorogood M, Hannaford PC. The influence of oral contraceptives on the risk of multiple sclerosis. Br J Obstet Gynaecol 1998;105:1296-1299.

32. Ramagopalan SV, Lee JD, Yee IM, et al. Association of smoking with risk of multiple sclerosis: a population-based study. J Neurol 2013;260:1778-1781.

33. Hedström AK, Baarnhielm M, Olsson T, Alfredsson L. Exposure to environmental tobacco smoke is associated with increased risk for multiple sclerosis. Mult Scler 2011;17:788-793.

34. Sundstrom P, Nystrom L, Hallmans G. Smoke exposure increases the risk for multiple sclerosis. Eur J Neurol 2008; 15:579-583.

35. Salzer J, Hallmans G, Nystrom M, Stenlund H, Wadell G, Sundstrom P. Smoking as a risk factor for multiple sclerosis. Mult Scler 2013;19:1022-1027.

36. Sundström P, Nystrom L. Smoking worsens the prognosis in multiple sclerosis. Mult Scler 2008;14:1031-1035.

37. Simon KC, van der Mei IA, Munger KL, et al. Combined effects of smoking, anti-EBNA antibodies, and HLADRB1*1501 on multiple sclerosis risk. Neurology 2010; 74:1365-1371.

38. Correale J, Farez MF. Smoking worsens multiple sclerosis prognosis: two different pathways are involved. J Neuroimmunol 2015;281:23-34. 


\section{Neurology \\ Neuroimmunology \& Neuroinflammation}

No association of tobacco use and disease activity in multiple sclerosis

Silje Kvistad, Kjell-Morten Myhr, Trygve Holmøy, et al.

Neurol Neuroimmunol Neuroinflamm 2016;3;

DOI 10.1212/NXI.0000000000000260

This information is current as of July 14, 2016

\section{Updated Information \& Services}

References

Citations

Subspecialty Collections

Permissions \& Licensing

Reprints including high resolution figures, can be found at:

http://nn.neurology.org/content/3/4/e260.full.html

This article cites 36 articles, 1 of which you can access for free at: http://nn.neurology.org/content/3/4/e260.full.html\#\#ref-list-1

This article has been cited by 2 HighWire-hosted articles: http://nn.neurology.org/content/3/4/e260.full.html\#\#otherarticles

This article, along with others on similar topics, appears in the following collection(s):

Cohort studies

http://nn.neurology.org//cgi/collection/cohort_studies

MRI

http://nn.neurology.org//cgi/collection/mri

Multiple sclerosis

http://nn.neurology.org//cgi/collection/multiple_sclerosis

Risk factors in epidemiology

http://nn.neurology.org//cgi/collection/risk_factors_in_epidemiology

Information about reproducing this article in parts (figures,tables) or in its entirety can be found online at:

http://nn.neurology.org/misc/about.xhtml\#permissions

Information about ordering reprints can be found online:

http://nn.neurology.org/misc/addir.xhtml\#reprintsus

Neurol Neuroimmunol Neuroinflamm is an official journal of the American Academy of Neurology.

Published since April 2014, it is an open-access, online-only, continuous publication journal. Copyright $(\odot$ 2016 American Academy of Neurology. All rights reserved. Online ISSN: 2332-7812.

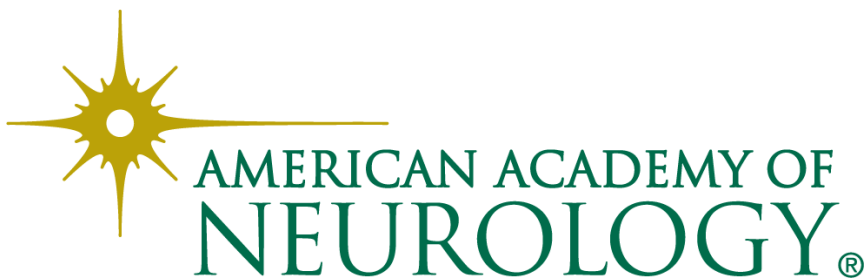

